\title{
Dissection Course in Anatomy as Stimulus to Independent Research and to a Real Step into Medicine
}

\author{
Vladimir Nikolenko ${ }^{1,2}$ Marine Oganesyan ${ }^{1} \quad$ Felix Zakirov $^{1} \quad$ Valentina Kudryashova $^{1}$ Nelly Rizaeva ${ }^{1}$ \\ Polina Valiullina ${ }^{1}$ \\ ${ }^{1}$ Department of Human Anatomy, First Moscow State Medical \\ University (Sechenov University), Moscow, Russia \\ 2 Department of Normal and Topographic Anatomy, Moscow State \\ Address for correspondence Felix Zakirov, Department of human \\ anatomy, First Moscow State Medical University (Sechenov University), \\ Mohovaya street, 11, 125009, Moscow, Russia (e-mail: nilski@mail.ru).
}

University, Moscow, Russia

J Morphol Sci 2019;36:63-66.

\begin{abstract}
Keywords

- anatomy

- cross-sectional anatomy

- dissection

- medical education

- methodology

Objectives In the recent years, many strategies in anatomy education have appeared. However, these innovations reduce the time students can spend on cadaver-based classes, which are considered to be an effective method of learning anatomy. The aim of the present research was to observe the advantages and features of dissection sessions in medical universities.

Materials and Methods The comparative analysis of the academic performance of dissector $(n=30)$ and nondissector $(n=105)$ students and a survey questionnaire were conducted. The data was collected through the work of the Dissection Mastery School (DMS) of the Sechenov University, Moscow, Russia, between 2016 and 2018. Results The data analysis showed significant higher examination results in the dissectors cohort $(p<0.001)$ and a strong opinion about dissection as a good tool to improve anatomy knowledge (95\% of responders). Apart from that, prosection is proven to have advantages in comparison with alternative learning approaches, according to researches performed by colleagues.

Conclusion These data show that dissection still remains one of the most effective and beneficial methods of teaching anatomy in medical universities, and that it should be further integrated into the medical curriculum.
\end{abstract}

\section{Introduction}

Anatomy is a basic medical science that provides necessary knowledge and forms a solid foundation for future doctors. Since the ancient times, the structure of the human body has been a topic of great interest. ${ }^{1}$ However, during the following centuries, dissection has faced criticism and oppression by religion and society. ${ }^{2}$ But the will of researchers to understand the human body has managed to overcome these difficulties to enrich anatomy knowledge. Thus, all the anatomy we learn and study today is the result of great enthusiasm.

Through the ages, anatomy did not lose its importance and still remains one of the first disciplines taught in the medical universities, as it provides the learning of further subjects. ${ }^{3}$ Obviously, there cannot be a qualified physician without knowledge of anatomy. Today, the process of teaching anatomy is being constantly improved and integrated with new technologies. ${ }^{4} \mathrm{As}$ a result of this rapid development of the anatomical sciences, more requirements relating to future doctors are imposed.

In addition to that, there is a tendency of reducing the curriculum of long-lasting disciplines, such as human anatomy. ${ }^{5}$ Often, the time allocated to the teaching of anatomy is only enough for a theoretical introduction to the subject and for a short visual overview into the human body. ${ }^{6}$ That is why, in spite of the large amount of available corpses, a significant shortage of time for cadaver prosection can be noticed. Under received

August 19, 2018

accepted

February 15, 2019
DOI https://doi.org/

10.1055/s-0039-1685222. ISSN 2177-0298.
Copyright $(2019$ by Thieme Revinter

Publicações Ltda, Rio de Janeiro, Brazil
License terms

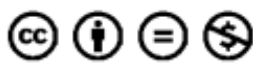


these circumstances, the necessity of practical classes with natural materials strongly increases, as anatomy is considered to be a classical morphological science.

The most detailed and comprehensive notion of the human body a future physician can get is only by being in contact with it. ${ }^{7}$ Dissection sessions provide important illustrative materials and proper learning of the structure of the human body. ${ }^{8}$ Therefore, today, cadaver dissection still remains an important aspect of teaching anatomy. Therefore, the aim of the present research was to value the role of practical dissection classes in learning anatomy by analyzing the academic performance of the students and summarizing their opinion regarding these classes.

\section{Materials and Methods}

In March 2016, the Dissection Mastery School (DMS) of the Sechenov University, Moscow, Russia, was launched. Any student was able to attend the School and learn the basics of dissection under the supervision of the human anatomy department professors. Two-hour length practical classes with cadavers were held twice a week in the evenings. During the classes, the students had an opportunity to work with cadavers individually or in groups.

\section{Recruitment}

Participation in the study was voluntary. During the 20172018 academic year, 135 first- and second-year students were selected for the research and divided into 2 groups, with 30 and 105 students, respectively. Members of the first group $(n=30)$ had been participating in current dissection schedule (dissectors). The second group of students $(n=105)$ did not attend the DMS classes (nondissectors). The academic performance in human anatomy of both groups was compared, according to the results of the diagnostic tests (DT), of the final exam (FE), and of the final test (FT). There was no bias for gender, for age, or for previous experience in anatomy. Informed consent was obtained from all of the participants.

\section{Examinations Structure}

The DT contained 20 questions of different types: multiplechoice, true/false, and matching. The FT included 30 questions of different types: multiple-choice, true/false, matching, and ordering. To observe the DT and FT results, a percentage of correct answers was calculated. The FE held in the end of the academic year included identifying anatomical structures, solving situational tasks, and an oral theoretical examination. After the interview with an independent examiner, the student was given a mark (excellent, average, or failure).

\section{Statistical Analysis}

To observe the efficiency of the dissection sessions and their impact on learning anatomy, the academic performance of the students on the FE was statistically analyzed. All of the data were collated and entered into Microsoft Excel (Microsoft Corporation, Redmond, WA, USA) and exported into STATA 13 software (StataCorp., College Station, TX, USA). To investigate the correlation, the chi-squared distribution $\left(X^{2}\right)$ was used. A value of $p \leq 0.005$ was considered statistically significant.

\section{Subjective Data Collection}

The survey was administered over a 3-day period at the conclusion of the course of DMS classes among students of the dissectors group $(n=35)$. All of the 35 students were asked to complete a questionnaire and share their opinion on dissection practice, measuring statements approval. To summarize the preferences and year of study distribution of the students, the review of two years of DMS work was composed. The results were compiled using Microsoft Excel.

\section{Results}

The results of the FE showed a significant difference between the 2 groups, with a higher performance in the $1^{\text {st }}$ group $(n=30)$ (-Table 1). The DMS students demonstrated more comprehensive and confident knowledge and were given better marks overall.

The overall pooled distribution of the FE marks showed a strongly significant correlation between attending practical classes with cadavers and higher academic performance on the FE ( $\left.\mathrm{X}^{2}=27.991 ; \mathrm{df}=3 ; p<0.0001\right)$.

The data analysis of the DT results ( - Table 2 ) also showed that the DMS participants demonstrated more comprehensive knowledge about subject units such as musculoskeletal, angiology, and peripheral nerves anatomy. Obviously, this fact was due to the opportunity to dissect and see those structures naturally at the DMS.

The average FT result was $88 \%$ in the DMS participants group and $74 \%$ in the control group. This significant difference indicates the efficiency of practical classes with cadavers in learning anatomy and correlates with the mentioned data.

Table 1 The final exam results

\begin{tabular}{|l|l|l|}
\hline \multirow{2}{*}{ Final exam result } & Number of students \\
\cline { 2 - 3 } & Dissectors & Nondissectors \\
\hline Failure & 0 & 1 \\
\hline Average & 1 & 29 \\
\hline Excellent & 29 & 75 \\
\hline
\end{tabular}

Table 2 Academic performance of students according to diagnostic tests

\begin{tabular}{|l|l|l|}
\hline Curriculum unit & $\begin{array}{l}\text { Attended } \\
\text { DMS classes }\end{array}$ & Average result, \% \\
\hline Musculoskeletal & + & 87 \\
\cline { 2 - 3 } & - & 76 \\
\hline \multirow{2}{*}{ Splanchnology } & + & 82 \\
\cline { 2 - 3 } & - & 74 \\
\hline Neurology & + & 86 \\
\cline { 2 - 3 } & - & 72 \\
\hline Angiology & + & 85 \\
\cline { 2 - 3 } & - & 71 \\
\hline
\end{tabular}




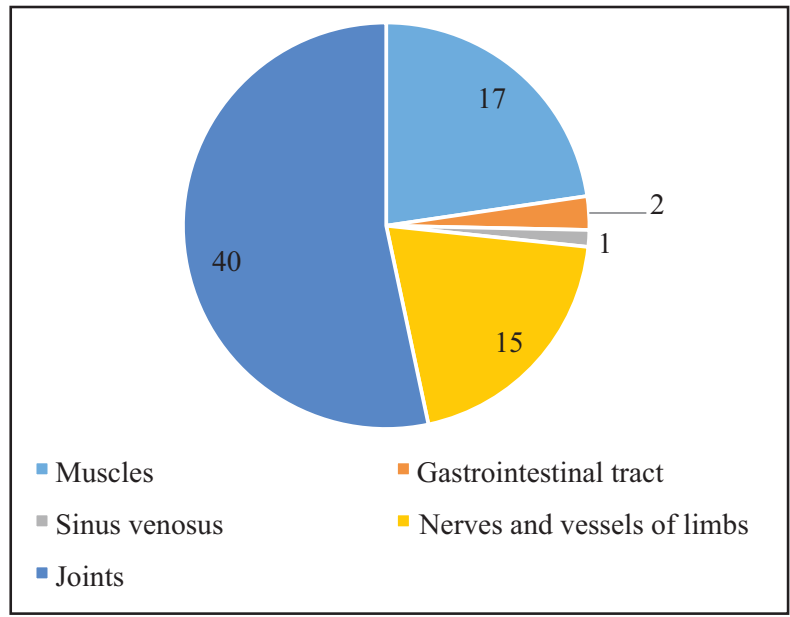

Fig. 1 The most preferred objects the students dissected.

According to the data of DMS work for 2 years, the most preferred objects for students to dissect were joints (total of 40 preparations). In addition to that, much attention was given to muscles, blood vessels and nerves (17 muscular and 15 preparations of blood vessels and nerves of limbs) (-Fig. 1).

The survey questionnaire results (summarized in - Table $\mathbf{3}$ ) showed that the students described the dissection practice in positive terms. Most of the responders confirmed the benefits and the efficiency of practical classes with cadavers in understanding gross anatomy and its necessity for every medical student. A small number of students (2 out of 30) were indifferent to dissection sessions and did not consider them as an effective method for learning anatomy. Almost one third of the responders (9 out of 30) did not agree that dissection classes have any impact on memorizing anatomical terms. A total of $95 \%$ of the responders agreed that dissection was a useful approach to learning anatomy.

The increased interest in dissection classes was proven according to the number of students who attended at the DMS. In the 2017-2018 academic year, there were 280 students in comparison to 113 in 2016-2017. The distribution of students in 2017-2018 is symbolic: most of the contingent comprised first- and second-year students. However, the analysis showed several more adult students who attended the DMS classes (-Fig. 2).

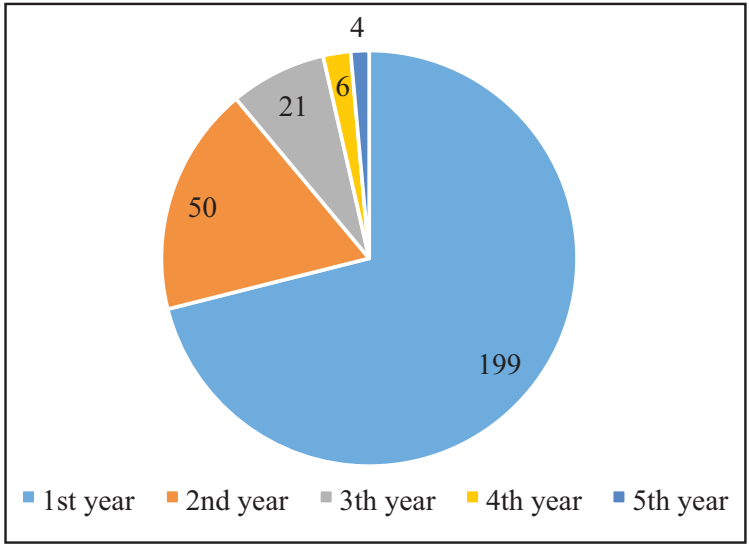

Fig. 2 Number of students who attended the DMS (year of study distribution).

\section{Discussion}

Dissection has a very long history, dating back to the first attempts to understand the structure of the human body. ${ }^{9}$ Despite the new technologies and innovations integrated to the educational process, prosection still remains an effective method in teaching anatomy. ${ }^{10}$ Data collected in the DMS show that dissection sessions improves academic performance and enriches the knowledge of human anatomy.

This point of view was also mentioned in other researches. Entwistle et al found that dissection classes helped students to combine their theoretical and practical skills to form the most comprehensive notion of the subject. ${ }^{11}$

The necessity of practical classes was also mentioned in the work of Pandey et al. ${ }^{12}$ They suggested that students encounter some difficulties in learning anatomy using only one method. According to the research, a combination of memorizing, theoretical revision, and practical dissection sessions resulted in the best achievements of students. Findings similar to ours were made by Yeager. ${ }^{13}$ That study included 4 examinations with 4 units in each, in which dissectors scored higher than nondissectors in 13 cases.

Despite the positive impact on the academic performance of the students, dissection classes have less obvious advantages, according to Crisp et al. ${ }^{14}$ The researchers concluded that prosection in the dissecting room develops teamwork

Table 3 Survey questionnaire results

\begin{tabular}{|l|l|l|l|l|l|}
\hline Statement about cadaveric dissection & \multicolumn{2}{|l|}{ Frequency, \% } & Strongly disagree \\
\cline { 2 - 7 } & Strongly agree & Agree & Neutral & Disagree & Stron \\
\hline A useful method of learning anatomy & 69 & 26 & 5 & - & - \\
\hline Helped to better understand gross anatomy & 57 & 34 & 9 & - & - \\
\hline Helped to memorize anatomical terms & 14 & 23 & 34 & 20 & 9 \\
\hline Helped to develop manual skills & 32 & 54 & 14 & - & - \\
\hline Is only necessary for future surgeons & - & - & 5 & 9 & 86 \\
\hline Would recommend dissection to classmates & 37 & 28 & 26 & 9 & - \\
\hline
\end{tabular}


and cooperation among students. These skills might be useful for practice in hospitals and in future jobs.

To observe the psychological aspect of dissection practice in medical universities, Bertman et al studied how classes with cadavers adapt students to accepting death. ${ }^{15}$ Researches stated that this experience would be useful in making an autopsy and dealing with terminal patients. Indeed, there are few medical specialties that do not face death during practice. Therefore, accepting death is an important stage of becoming a doctor, according to Marks et al. ${ }^{16}$

Another interesting finding that correlates with our results was made by Ellis. ${ }^{17}$ The scientist noticed that the hours spent by the students with cadavers had a positive impact on their manual skills, as well as on their knowledge about gross anatomy. This aspect of dissection practice might be useful for students who choose the path of a surgeon. This opinion was also confirmed by Sheikh et al, who used a survey questionnaire among 80 practicing surgeons of different specialties. ${ }^{18}$ Responders chose dissection as the most preferred method of learning human anatomy.

In the recent years, an impressive number of alternative methods of learning anatomy approach. Sometimes, dissection is being totally replaced by the use of new technologies, or changes in the medical curriculum leave a short amount of time for dissection, according to Bouwer et al and to Whelan et al. ${ }^{19,20}$ Every method has its unique features and advantages, mostly because of opportunities of vital study, visual quality, and ethical aspects. However, according to Estai et al, who composed a comparative analysis of all teaching and learning techniques that are used in medical universities nowadays, these methods have serious disadvantages in comparison to dissection. ${ }^{21}$ New technologies achieve high accuracy visualization, but still cannot replace the experience of tactile contact with the human body and of obtaining a correct notion of its texture, according to Van Wyk et al and to Burgess et al. ${ }^{22,23}$

\section{Conclusion}

Our study suggests that medical students consider dissection to have a positive impact on their knowledge and manual skills. According to the research results and data collected at the DMS of the Sechenov University, practical classes with cadavers provide students with an opportunity to improve academic performance and effectively learn human anatomy. Moreover, classical dissection demonstrates serious advantages in comparison to other methods used in the modern curriculum. The knowledge and skills obtained by the students from dissection can be useful for physicians of any specialty and qualification.

\section{Conflicts of Interests}

The authors have no conflicts of interests to declare.

\section{Acknowledgment}

The present research received no specific grant from any funding agency in the public, commercial, or not-for-profit sectors.

\section{References}

1 Ferngren G. Vivisection Ancient and Modern. Hist Med 2017;4 (03):243-254

2 Izutkin DA. History of forming fundamentals of scientific anatomy. Medicinskij al'manah 2017;(02):38-41

3 Ivanenko GA, Kuznetsov AV. Teaching of human anatomy in medical university: problems and prospects. Journal of Anatomy and Histopathology. 2017;6(05):16

4 Kuznecova MA, Miroshkin DV, Chilingaridi SN. Methodological approaches to the teaching of human anatomy in modern conditions. Morphology 2017;151(03):79-80(In Russian)

5 Winkelmann A. Anatomical dissection as a teaching method in medical school: a review of the evidence. Med Educ 2007;41(01):15-22

6 Borovleva OV, Martynchuk DV, CHerdanceva DD, Batuhtina NP, Efremova VP, Sindeeva LV. Classic and innovative methods in the educational-research work of students studying the discipline "human anatomy. Modern issues of science and education 2015;(05):190. (In Russian) Classic and innovative methods in the educational-research work of students studying the discipline "human anatomy

7 Nikolenko VN, Oganesyan MV, Kudryashova VA, Rizaeva NA, Shumak AV. What can bring teaching of anatomy to the requirements (needs) of medical practice? Modern issues of science and education 2017;(03):65-70

8 Griksaitis MJ, Sawdon MA, Finn GM. Ultrasound and cadaveric prosections as methods for teaching cardiac anatomy: a comparative study. Anat Sci Educ 2012;5(01):20-26

9 Ghosh SK. Human cadaveric dissection: a historical account from ancient Greece to the modern era. Anat Cell Biol 2015;48(03):153-169

10 Larkin TA, McAndrew DJ. Factors influencing students' decisions to participate in a short "dissection experience" within a systemic anatomy course. Anat Sci Educ 2013;6(04):225-231

11 Entwistle N, Tait H. Approaches to studying and perceptions of the learning environment across disciplines. New Dir Teach Learn $1995 ; \cdots: 03-103$

12 Pandey P, Zimitat C. Medical students' learning of anatomy: memorisation, understanding and visualisation. Med Educ 2007;41(01):7-14

13 Yeager VL. Learning gross anatomy: dissection and prosection. Clin Anat 1996;9(01):57-59

14 Crisp AH. The relevance of anatomy and morbid anatomy for medical practice and hence for postgraduate and continuing medical education of doctors. Postgrad Med J 1989;65(762):221-223

15 Bertman SL, Marks SC Jr. Humanities in medical education: rationale and resources for the dissection laboratory. Med Educ 1985;19(05):374-381

16 Marks SC Jr, Bertman SL, Penney JC. Human anatomy: a foundation for education about death and dying in medicine. Clin Anat 1997;10(02):118-122

17 Ellis H. Teaching in the dissecting room. Clin Anat 2001;14(02): 149-151

18 Sheikh AH, Barry DS, Gutierrez H, Cryan JF, O'Keeffe GW. Cadaveric anatomy in the future of medical education: What is the surgeons view? Anat Sci Educ 2016;9(02):203-208

19 Bouwer HE, Valter K, Webb AL. Current integration of dissection in medical education in Australia and New Zealand: Challenges and successes. Anat Sci Educ 2016;9(02):161-170

20 Whelan A, Leddy JJ, Ramnanan CJ. Benefits of extracurricular participation in dissection in a prosection-based medical anatomy program. Anat Sci Educ 2018;11(03):294-302

21 Estai M, Bunt S. Best teaching practices in anatomy education: A critical review. Ann Anat 2016;208:151-157

22 Van Wyk J, Rennie CO. Learning Anatomy Through Dissection: Perceptions of a Diverse Medical Student Cohort. Int J Morphol 2015;33(01):89-95

23 Burgess A, Ramsey-Stewart G. Elective anatomy by whole body dissection course: what motivates students? BMC Med Educ $2014 ; 14: 272$ 